\title{
Taxonomía y distribución de las hormigas del género Tapinoma (Formicidae: Dolichoderinae) en Colombia
}

\author{
Taxonomy and distribution of Tapinoma ants (Formicidae: Dolichoderinae) in Colombia
}

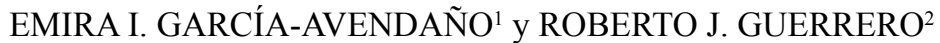

\begin{abstract}
Resumen: Se revisa por primera vez el género Tapinoma en Colombia, a partir de material depositado en colecciones biológicas y de recolecciones esporádicas en el territorio nacional. Se reconocen las especies T. litorale, T. melanocephalum y T. ramulorum y una cuarta sin describir. También se provee una clave taxonómica basada en las obreras, así como imágenes y mapas de las especies presentes en el país.
\end{abstract}

Palabras clave: Biodiversidad, claves taxonómicas, especies invasoras, nuevos registros, región Neotropical.

\begin{abstract}
The species of the genus Tapinoma are reviewed for the first time in Colombia. The species T. litorale, T. melanocephalum and T. ramulorum are recognized, as well one fourth undescribed species. A taxonomic key based on the workers, images and distribution maps are provided.
\end{abstract}

Key words: Biodiversity, taxonomic keys, trap species, new records, Neotropical region.

\section{Introducción}

El género Tapinoma fue descrito por Föerster (1850) con base en la especie-tipo Tapinoma collina Föerster (=Tapinoma erraticum (Latreille, 1798) sinónimo mayor). Las hipótesis filogenéticas sugieren que este género de hormigas comprende un grupo monofilético (Ward et al. 2010), cuyo registro fósil es conocido desde mediados del Eoceno (40-60 Ma) (Dlussky y Perkovsky 2002). La evidencia morfológica sugiere que Tapinoma comparte un ancestro reciente con $\mathrm{Te}$ chnomyrmex (Shattuck 1995); sin embargo, los análisis moleculares sugieren que, a pesar de su similitud morfológica, estos dos géneros se encuentran en clados separados dentro de la tribu Tapinomini: Technomyrmex es género hermano de Axinidris mientras que Tapinoma lo es de Aptinoma (Ward et al. 2010).

Morfológicamente, las hormigas del género Tapinoma se caracterizan por poseer mandíbulas con margen masticador armado de 3-7 dientes grandes, seguidos por una hilera continua de más de 7 dentículos, sin margen basal diferenciado; fórmula palpal 6,4; escama del pecíolo reducida o vestigial, además pecíolo oculto por el primer tergo gastral, usualmente invisible en vista dorsal; en la misma vista sólo cuatro segmentos del gáster son visibles, el quinto tergo se encuentra doblado por debajo del cuarto, donde forma una placa transversal apoyada en el quinto esterno, así los orificios anales y asociados se encuentran en posición ventral (Shattuck 1992; Bolton 1994; Cuezzo 2003).

Al presente, Tapinoma actualmente cuenta con 69 especies y 26 subespecies válidas (Bolton 2017). Aunque este género es abundante y diverso en regiones zoogeográficas como la Paleártica (Bolton 2017), al parecer no existe una comprensión taxonómica de sus especies, lo que sugiere posibles errores en la nomenclatura y la clasificación (Fisher y Bolton 2007); así mismo, la información sobre diversidad regional del grupo es escasa y no se ha hecho un inventario completo para países diversos como Brasil o Colombia. En este último, Fernández y Sendoya (2004) registran a Tapinoma melanocephalum (Fabricius, 1793) como la única especie de este género; sin embargo, la visita a colecciones biológicas nacionales (p. ej.: Instituto Alexander von Humboldt) permitió identificar algunas formas diferentes, las cuales se describen en este trabajo. Con base en lo anterior, el objetivo de la siguiente investigación fue realizar un estudio taxonómico del género Tapinoma en Colombia. Además, al no existir claves para la identificación de las especies del género (Cuezzo 2003), se presenta por primera vez una clave taxonómica local (i.e. especies para Colombia) que permitirá avanzar en el conocimiento de las hormigas Tapinoma en países circunvecinos y la región Neotropical.

\section{Métodos}

Especímenes. Se examinaron 361 individuos (331 obreras, 18 reinas y 12 machos) de Tapinoma durante las visitas a museos y colecciones entomológicas de diferentes instituciones nacionales y extranjeras, así como recolectas en áreas urbanas en municipios de Colombia y la Sierra Nevada de Santa Marta (Magdalena). Las colecciones entomológicas visitadas y utilizadas para el depósito de los ejemplares se abrevian a continuación: CBUMAG, Colección Entomológica del Centro de Colecciones Biológicas de la Universidad del Magdalena, Santa Marta, Colombia.

CEUA, Colección Entomológica de la Universidad de Antioquia, Medellín, Colombia.

CGIBEMH, Colección del grupo de investigación en biología, ecología y manejo de hormigas, Universidad del Valle, Santiago de Cali, Colombia.

CWEM, Colección de William y Emma Mackay, Universidad de Texas, El Paso, Texas, Estados Unidos de América.

\footnotetext{
${ }^{1}$ Bióloga. Grupo de Investigación en Insectos Neotropicales. Universidad del Magdalena. Carrera 32 № 22-08. San Pedro Alejandrino, Santa Marta, Colombia, emisagave@gmail.com. ${ }^{2}$ Doctor en Zoología. Grupo de Investigación en Insectos Neotropicales. Universidad del Magdalena. Carrera 32 N² 22-08. San Pedro Alejandrino, Santa Marta, Colombia, rguerrero@unimagdalena.edu.co. Autor para correspondencia: Roberto J. Guerrero. Doctor en Zoología. Grupo de Investigación en Insectos Neotropicales. Universidad del Magdalena. Carrera 32 № 22-08. San Pedro Alejandrino, Santa Marta, Colombia, rguerrero@ unimagdalena.edu.co.
} 
IAvH, Colección Entomológica del Instituto de Investigación de Recursos Biológicos Alexander von Humboldt, Villa de Leyva, Colombia.

ICN, Museo de Historia Natural, Instituto de Ciencias Naturales, Universidad Nacional de Colombia, Bogotá, Colombia.

JKWC, Colección personal de James K. Wetterer, Florida, Estados Unidos de Norte América.

MEFLG, Museo Entomológico Francisco Luis Gallego, Universidad Nacional de Colombia, Medellín, Colombia.

MPUJ, Museo de la Pontificia Universidad Javeriana, Bogotá, Colombia.

MUSENUV, Museo de Entomología de la Universidad del Valle, Santiago de Cali, Colombia.

MZUSP, Museo de Zoología de la Universidad de São Paulo, São Paulo, Brasil.

Análisis morfológico. Los caracteres morfométricos se examinaron en la casta obrera de todas las especies; solo en algunas fueron incluidas hembras reproductoras (i.e. ginas aladas y sin alas) y machos.

Todas las medidas se tomaron en aumento de 96X con un estereomicroscopio Zeiss Stemi 305 y micrómetro ocular adaptado de precisión $0,01 \mathrm{~mm}$. Las siguientes mediciones se expresan en milímetros (mm): Longitud de la cabeza (LC), en vista frontal, la distancia entre dos líneas paralelas desde el margen posterior de la cabeza hasta el margen anterior del clípeo. Ancho de la cabeza (AC), en vista frontal, medido el ancho máximo de la cabeza, excluyendo los ojos. Longitud del escapo (LE), longitud del escapo antenal, excluyendo el cóndilo y su conexión con la antena. Longitud de Weber (LW), en vista lateral o de perfil, tomada en diagonal desde el extremo posterior del pronoto, hasta el ángulo metasternal. Otras medidas como la longitud de la tibia posterior y ancho del pronoto también fueron tomadas, pero no mostraron variación interespecífica, por lo tanto, fueron excluidas.

Índices. Índice cefálico (IC): (AC/LC) x 100. Índice del escapo (IE): (LE /LC) x 100.

También se examinaron diferentes caracteres morfológicos tales como pilosidad, coloración del cuerpo, forma del propodeo, coloración y forma de las mandíbulas y morfología de los palpos maxilares. La descripción de la superficie corporal de obreras, hembras reproductoras y machos se basó en Harris (1979).

Distribución geográfica. Los mapas se generaron utilizando el programa de computador QGIS 2.16 (http://www.qgis.org/ es/site/). La información latitudinal y longitudinal fue extraída de las etiquetas de los ejemplares; sin embargo, en el caso de los ejemplares sin coordenadas, pero con localidad se utilizó el gacetero geográfico electrónico (Falling Rain Software, Ltd. 2017) para obtener coordenadas aproximadas.

Fotografías. Las fotografías multifoco se tomaron con un microscopio estereoscopio automatizado Leica M205A, acoplado con una cámara Leica DFC450 y generadas utilizando el paquete computacional Leica LAS Montaje. El brillo y contraste fueron mejorados con Corel PHOTO PAINT $^{\circledR}$ 2017; las planchas fueron organizadas utilizando Corel DRAW ${ }^{\circledR} 2017$.

\section{Resultados}

Se reconocen cuatro especies del género Tapinoma en Colombia: T. litorale Wheeler, 1905 y T. melanocephalum (Fabricius, 1793), ambas con ampliación de sus distribuciones dentro del territorio nacional; T. ramulorum Emery, 1896 con la mayoría de registros en la región andina colombiana y Tapinoma sp. con una distribución geográfica y ecológica disyunta.

\section{Clave para las especies de Tapinoma en Colombia, basada en obreras}

1. Ojos compuestos muy pequeños, con menos de ocho facetas en la máxima longitud; cabeza semicuadrada, con el vértice posterior recto a suavemente cóncavo; cuerpo marrón claro o amarillento, las poblaciones de Colombia son totalmente amarillentas .................................................. 2 - Ojos relativamente grandes, con más de ocho facetas en la máxima longitud; cabeza es notablemente variable en forma, desde oblonga hasta globosa con los márgenes laterales muy convexos, con el vértice posterior recto, ligeramente cóncavo a fuertemente excavado en el centro; cuerpo variable en color ........................................................ 3 2. Escapos alcanzando o sobrepasando las esquinas posteriores de la cabeza; margen anterior del clípeo recto transverso; sin pelos erectos entre las carenas frontales (vista dorsal de la cabeza); pronoto sin pelos erectos en la superficie dorsal .................................................. T. litorale - Escapos alcanzando el límite posterior de las 2/3 partes de la cápsula cefálica; margen anterior del clípeo ligeramente sinuoso formando esquinas o ángulos romos sobresalientes con los bordes anterolaterales; dos pares de pelos entre las carenas frontales, un par inferior y otro superior; pronoto con dos pelos erectos en la superficie dorsal

Tapinoma sp.

3. Grandes; con la cabeza semicuadrada, tan ancha como larga; margen masticador de la mandíbula fuertemente armado, con cinco dientes conspicuos; segmentos 2 y 3 de los palpos maxilares delgados y alargados; cabeza, mesosoma y metasoma completamente marrón oscuro a claro; patas coloreadas distintivamente, trocánteres amarillentos, fémures marón, tibias, tarsos y uñas amarillentas

T. ramulorum

- Pequeñas, casi que imperceptibles; con la cabeza ovoide, más larga que ancha; margen masticador con sólo diente apical y subapical conspicuo (algunas veces un 3er diente relativamente grande); segmentos 2 y 3 de los palpos maxilares en forma de espátula (este carácter es polimórfico, con variación intracolonial en las obreras); cabeza y mesosoma varia de marrón oscuro a claro, metasoma completamente amarillo pálido casi transparente; patas completamente pálidas, casi hialinas T. melanocephalum

\section{Sinopsis de especies}

\section{Tapinoma litorale Wheeler, 1905}

(Figs. 1, 6A)

Medidas de la obrera. $(\mathrm{n}=25)$ : LC: $0,48-0,52$; AC: 0,40-0,43; LE: 0,40-0,47; LW: 0,46-0,49; IE: 81-103; IC: $81-90$ 


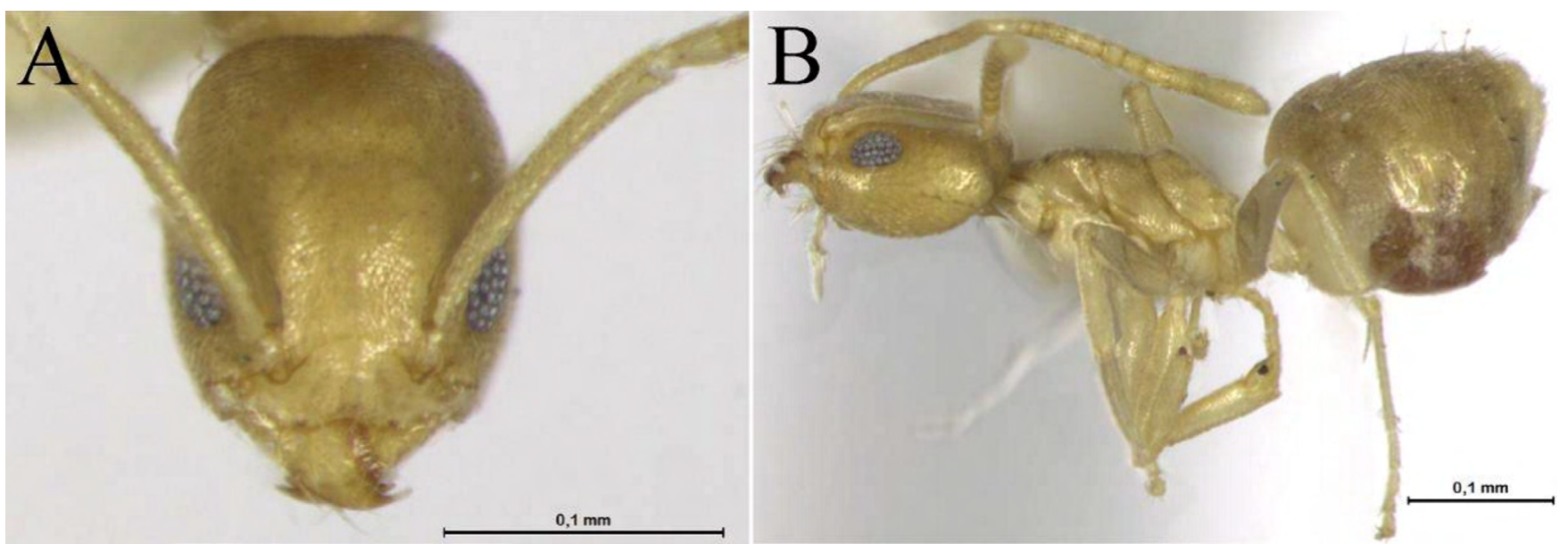

Figura 1. Hábito de T. litorale. A. Vista frontal de la cabeza de la obrera. B. Vista lateral de la obrera.

Diagnosis de la obrera. Hormigas pequeñas (LW: 0,46$0,48)$, de color amarillo a marrón claro, con escapos relativamente largos que alcanzan o sobrepasan las esquinas posterolaterales de la cabeza, sin pelos en las carenas frontales ni en el pronoto (Fig. 1).

Descripción de la obrera. Cabeza. Cápsula cefálica semirectangular, en vista frontal más larga que ancha, mayor amplitud de la cápsula por encima de los ojos; márgenes laterales ligeramente convexos; margen occipital recto, con una concavidad amplia pero somera en el vértex; esquinas posterolaterales redondeadas continuándose sin interrupción hacia los márgenes laterales. Mandíbulas relativamente pequeñas, semitriangulares, con el margen externo recto en la porción medio-posterior y fuertemente curvado hacia el margen masticador, este último con la siguiente dentición: un diente apical triangular más largos que ancho, diente subapical $1 / 4$ más pequeño que el diente apical, 3er diente triangular más pequeño que el anterior, 4to diente similar en forma y tamaño al 2 do diente, 5to diente más pequeño que el 3er diente, seguido de dientes minúsculos que disminuyen en tamaño convirtiéndose en un margen aserrado que se continua hasta el margen basal indiferenciado donde el borde aserrado se diluye de forma imperceptible hacia la inserción de las mandíbulas. En vista dorsal, margen anterior del clípeo con una concavidad amplia, somera, en algunos casos profunda, con esquinas redondeadas continuándose hacia los márgenes laterales del clípeo; por encima de la concavidad una depresión apenas impresa, de forma triangular; margen posterior del clípeo fuertemente convexo, proyectándose entre las carenas frontales más allá de las inserciones antenales. Carenas frontales fuertemente marcadas. Antenas con 12 segmentos, escapos antenales de longitud variable siempre alcanzando el vértice posterior cefálico o sobrepasándolo por una longitud igual al 2do segmento antenal; pedicelo más largo que ancho, en forma de cono, 2do segmento cuadrado, el resto de segmentos antenales en forma de barril, último segmento tan largo como la sumatoria de los dos segmentos que le preceden, más ensanchado que el resto de los segmentos antenales, como una maza antenal. Ojos pequeños con menos de ocho facetas en su máxima longitud, ubicados por debajo de la mitad de la longitud de la cabeza, generalmente por debajo del máximo ancho de la cápsula cefálica.

Mesosoma: Hormigas pequeñas. En vista dorsal pronoto de forma trapezoidal, cara anterior más ancha que la pos- terior, hombros pronotales fuertemente proyectados hacia afuera; mesonoto en forma rectangular más largo que ancho, espiráculo mesonotal pequeño y redondo, en forma de anillo. En vista lateral, promesonoto convexo, en línea continua hasta la cara dorsal del propodeo, esta última recta y angosta, un poco levantada hacia el ápice, cayendo abruptamente en un declive largo, cuatro veces más largo que la cara dorsal, recto e inclinado; espiráculo propodeal pequeño y circular, con reborde asemejándose a un anillo, sobresaliendo de la superficie propodeal, ubicado dentro y a la mitad del declive propodeal; surco metapleural marcado en una línea delgada; complejo propodeo-metapleura de forma rectangular con lados paralelos, más largo que ancho.

Metasoma: Peciolo sin escama, cara dorsal de recta a sinuosa, cara ventral con lóbulo posteroventral conspicuo; 1er tergo más ancho que el resto.

Superficie corporal y pilosidad: Cápsula cefálica vista de frente reticulada-alveolada, opaca a brillante, tapizada con abundante pubescencia amarillenta muy corta. Superficie dorsal de las mandíbulas lisa y brillante, con pelos amarillentos largos y espaciados entre sí, pelos un poco más largos cerca del margen masticador. Superficie dorsal del clípeo reticulado, desprovisto de pilosidad excepto por la porción central que está tapizada de pilosidad amarillenta muy corta, casi imperceptible; reborde anterior del clípeo con un par de pelos dirigidos hacia el interior de la concavidad, en toda la esquina curva de la muesca clipeal, un par de pelos erectos dirigidos hacia el frente y relativamente cortos, ubicados un poco por encima del ángulo que forman los márgenes laterales del clípeo y los márgenes laterales de la concavidad media, cada una reposando en una fóvea conspicua, más oscura que la coloración del clípeo y un par de pelos relativamente largos en el reborde de los márgenes laterales, resto del reborde anteroclipeal cubierto de pequeños pelos dirigidos hacia adentro. Escapos tapizados de abundante pilosidad corta amarillenta, recostada y espaciada; segmentos antenales finamente punteados y con abundante pilosidad corta, semirecostada, sobresaliendo de los contornos de los segmentos antenales.

Mesosoma en vista dorsal cubierto de tenues alveolos y puntuaciones finas. Tagma cubierto de pilosidad corta, amarillenta, espaciada y recostada sobre la superficie; en vista lateral, mesopleura relativamente brillante, reticulada/alveolada. Coxas y patas cubiertas con pilosidad amarillenta, similar al resto del mesosoma. 


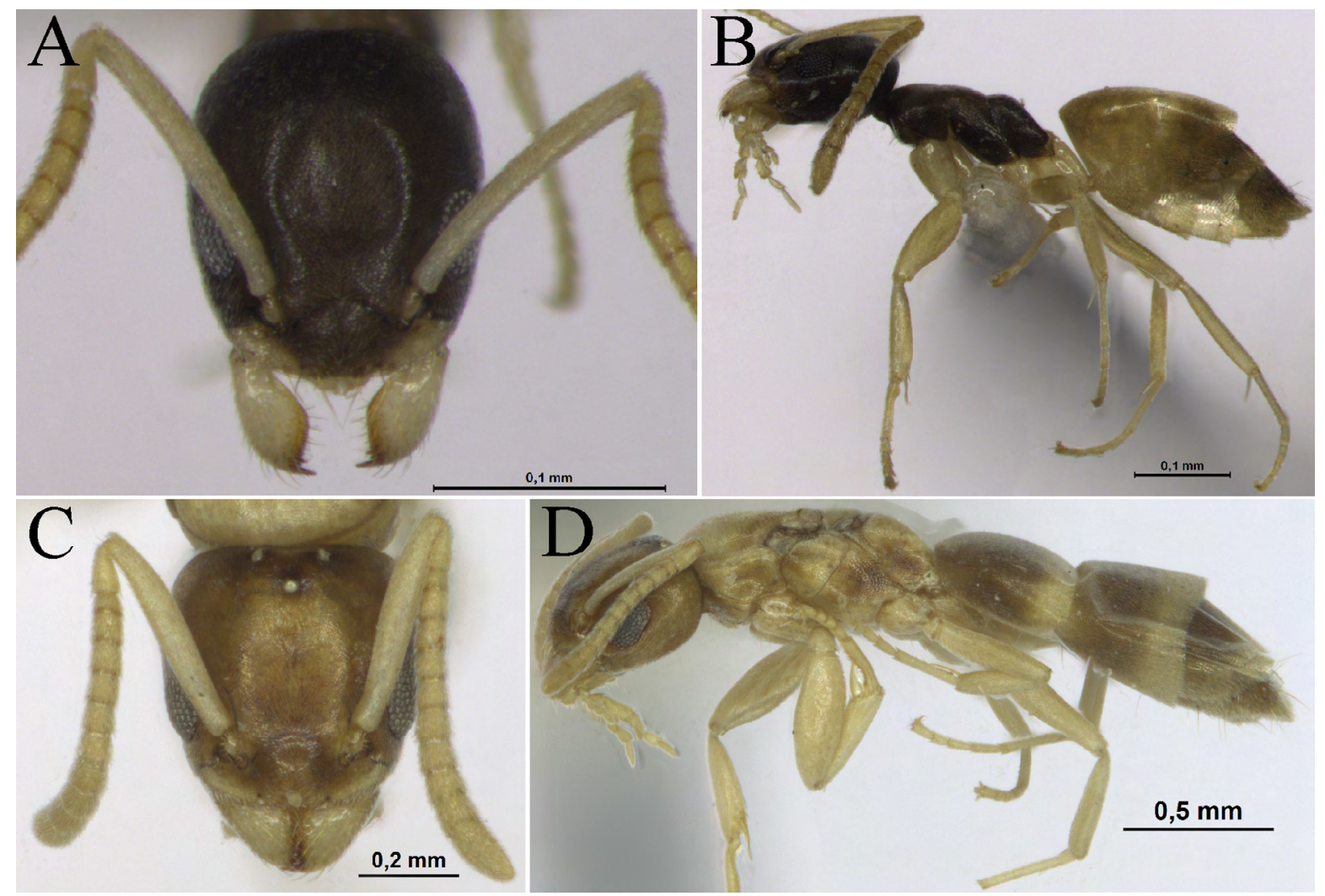

Figura 2. Hábito de T. melanocephalum. A. Vista frontal de la cabeza de la obrera. B. Vista lateral de la obrera. C. Vista frontal de la cabeza de la reina. D. Vista lateral de la reina.

Cara dorsal del peciolo lisa, cara posterior del lóbulo frontal con pelos gruesos semirecostados. Gáster cubierto de abundante pilosidad amarillenta, más larga que el resto del cuerpo; 2do tergo con dos pelos gruesos en la mitad de la placa, 3er tergo con cuatro pelos, cuarto tergo con dos pelos, cada uno reposando en una fóvea conspicua más oscura que la coloración del gáster.

Coloración: Hormigas generalmente de color amarillo pálido a marrón claro, uniformemente coloreadas. Margen masticador, rojizo a marrón oscuro, gáster a veces más oscuro que el resto del cuerpo.

Distribución. Departamentos del Cesar, Magdalena, y San Andrés y Providencia, los dos últimos registrados en Wetterer y Guerrero (2017). Se registra por primera vez poblaciones de T. litorale para el departamento del Cesar (inmediaciones de Chiriguaná), en ambientes de sabana. En el Magdalena, las poblaciones de esta especie son alopátricas; es posible encontrarlas tanto a $30 \mathrm{msnm}$ en el PNN Tayrona como a 1.300 msnm en la Sierra Nevada de Santa Marta (Fig. 6A).

Biología. En la región caribe colombiana se recolectaron especímenes de T. litorale mediante el método manual, en bosque tropical montano $(1.300 \mathrm{msnm})$ y en bosque seco tropical (Parque Nacional Natural Tayrona). Las poblaciones en el Cesar fueron recolectadas directamente de un nido en el envés de una hoja muerta de palma (Phoenix dactylifera L., 1753) creciendo en ambiente de sabana.

Material examinado: COLOMBIA. Cesar. 5 obreras. Chiriguaná. Finca El Recuerdo. 9²6’N 73³1'O, 60 m. Re- colecta manual. 04-ene-2015. Guerrero, R.J. [CBUMAG]. Magdalena. 35 obreras. $9 \mathrm{Km}$ SE Minca. Vda Vista nieves. 11,08972 -74,06021, $1650 \mathrm{~m}$. Recolecta manual. 28-may2017. Longino, J.T. (JTL-9843) [CBUMAG]. 2 obreras. Minca. El Campano. $11^{\circ} 7^{\prime} \mathrm{N} 74^{\circ} 6$ 'O, $1300 \mathrm{~m}$. Recolecta manual. 13-sep-1985. Ward, P.S. [PSWC]. 2 obreras. Santa Marta. Minca. El Campano. $11^{\circ} 7^{\prime} \mathrm{N} 74^{\circ} 6^{\prime} \mathrm{O}, 1300 \mathrm{~m}$. Recolecta manual. 13-sep-1985. Ward, P. S. [ICN]. 1 obrera. Parque Nacional Natural Tayrona -PNNT. 15-jun-1976. Martinez, E. [IAvH-E]. 1 obrera. Parque Nacional Natural Tayrona PNNT. Cañaveral. Cabo San Juan del Guía. 21-may-1977. Kluger, C. [IAvH-E]. 1 obrera. San Andrés, Providencia y Santa Catalina. Si más información. [JKWC].

\section{Tapinoma melanocephalum (Fabricius, 1793)} (Figs. 2-3, 6B)

Medidas de la obrera. $(\mathrm{n}=24)$ : LC: $0,40-0,48$; AC: $0,37-$ 0,42; LE: 0,38-0,46; LW: 0,38-0,50; IE: 88-100; IC: 80-95.

Diagnosis de la obrera. Obreras bicoloreadas, cápsula cefálica y mesosoma color marrón oscuro, opaco o brillante; metasoma, patas, coxas y antenas amarillo pálido, casi hialinos. Ojos relativamente grandes, con ocho o más facetas en su máxima longitud. 2do y 3er segmento de los palpos maxilares generalmente en forma de espátula (Fig. 3).

Descripción de la obrera. Cabeza: Cápsula cefálica ovoide, en vista frontal más larga que ancha, mayor amplitud de la cápsula un poco por encima o a la altura de los ojos; márgenes laterales convexos, margen occipital convexo, 


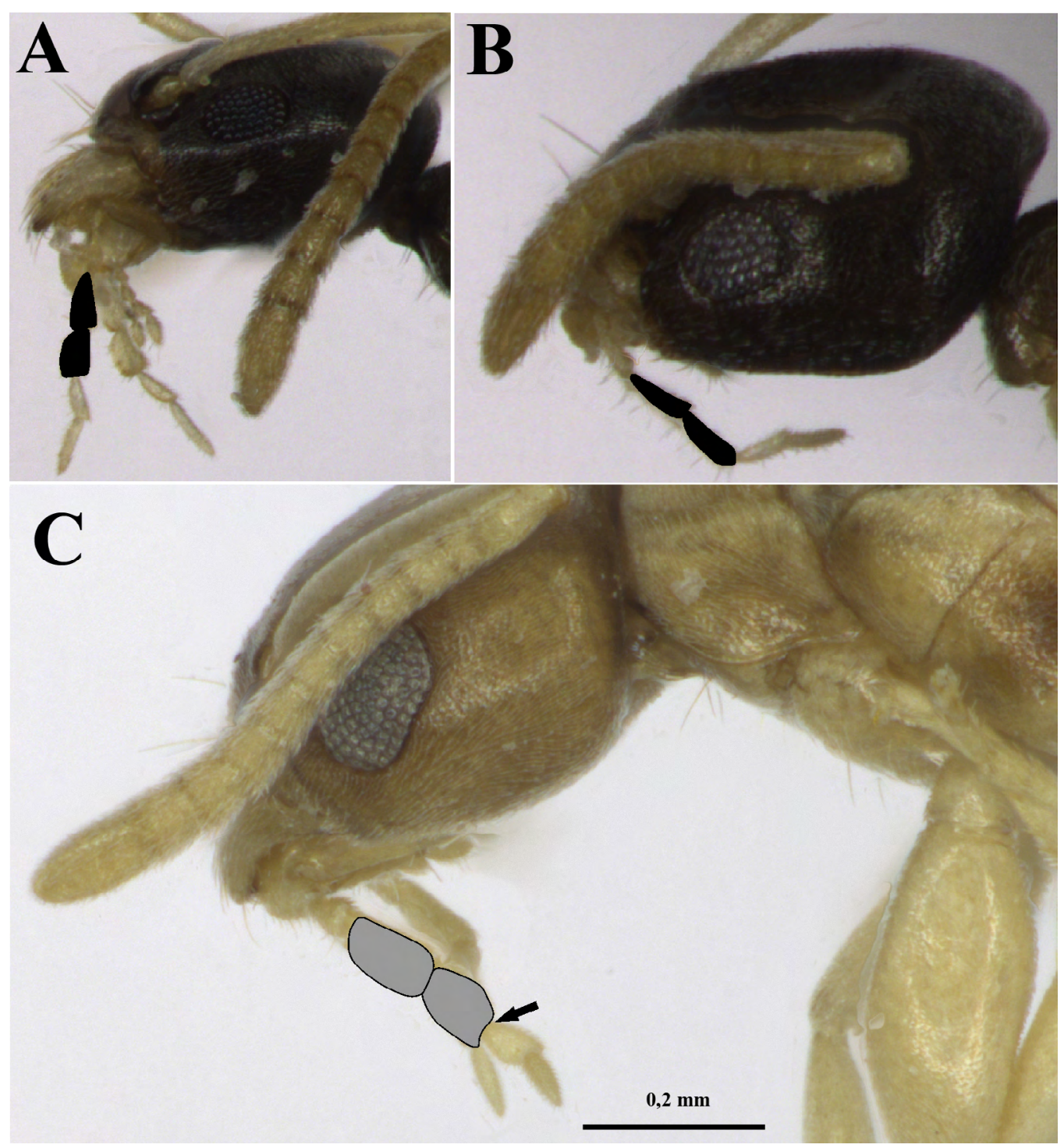

Figura 3. Cabezas de las obreras y la reina de T. melanocephalum. A y B. Polimorfismo en los palpos maxilares de la obrera. C. Palpos maxilares ensanchados en la reina (la flecha indica la inserción del quinto segmento en la cara interna del cuarto segmento).

en algunos casos con una pequeña hendidura somera en el vértex, relativamente estrecha; esquinas posterolaterales redondeadas; mandíbulas semitriangulares, con el margen externo recto en la parte medio-posterior y fuertemente curvada en la parte medio-anterior llegando al margen interno; margen masticador armado de un solo diente apical y subapical conspicuo, algunas veces pueden tener un $3 \mathrm{er}$ diente relativamente grande; margen basal indiferenciado y completamente aserrado, ambos márgenes continuos sin ángulos o esquina que los limite, borde aserrado diluyéndose de forma imperceptible hacia la inserción de la mandíbula. 2do y 3er segmento de los palpos maxilares ensanchados o alargados sin ensanchamiento, con variación intracolonial solo en las obreras (Fig. 3). En vista frontal, el borde anterior del clípeo de forma cóncava, a veces con una pequeña concavidad somera en el vértice relativamente amplia; margen posterior del clípeo fuertemente arqueado proyectándose apenas entre las bases de las inserciones antenales. Antenas con 12 segmentos, escapos antenales alcanzando o sobrepasando el borde posterior cefálico, primer segmento o pedicelo en forma de cono más largo que ancho, ensanchándose hacia el 2 do segmento; 2 do segmento antenal cuadrado, más pequeño que el resto de los segmentos; 3er-9no segmentos rectangulares, último segmento tan largo como la suma del 8vo y 9no segmento, a veces más ensanchado que los segmentos que le preceden y otras terminando en forma de punta. Ojos grandes con ocho o más facetas en su máxima longitud, ubicados por debajo de la mitad de la máxima longitud de la cápsula cefálica, a la altura del máximo ancho de la cabeza.

Mesosoma: En perfil, pronoto y mesonoto formando una convexidad continua, línea pre-mesonotal tenue similar a una incisión, marcada pero no profunda. En vista dorsal, pronoto trapezoidal y mesonoto en forma de trapecio isósceles, más ancho en la parte anterior que en la posterior. Propodeo en vista lateral con la cara corta, angulada, cayendo en declive largo; espiráculo propodeal circular, pequeño, con reborde asemejándose a un anillo, sobresaliendo de la superficie propodeal, ubicado por debajo de la línea del declive. 
Metasoma: Peciolo sin escama; primer segmento gastral notablemente más largo y con superficie más amplia que el resto.

Superficie corporal y pilosidad: Cápsula cefálica vista de frente tapizada de abundante pilosidad fina y muy corta; superficie dorsal de la mandíbula con abundantes pelos amarillentos largos semierectos, separados entre sí, a una distancia relativamente corta para su longitud; pelos más largos en el margen interno, cerca del borde masticador. Superficie dorsal del clípeo con abundante pilosidad corta y en el borde anterior del clípeo un par de setas proyectadas hacia el frente, cada una reposando en una fóvea conspicua, más oscura que la coloración del clípeo. Escapos cubiertos de pilosidad corta y recostada sobre la superficie; segmentos antenales con abundantes pelos amarillentos, relativamente largos, separados entre sí dejando ver la superficie de los artejos. Mesosoma totalmente reticulado. Peciolo liso. En el último segmento del gáster se encuentra una configuración de ocho pelos erectos.

Coloración: Hormiga generalmente con cápsula cefálica y mesosoma de color marrón oscuro, algunas veces los individuos poseen una mancha amarillenta que cubre la parte posterior del pronoto y todo el mesonoto; con mandíbulas, escapos, segmentos antenales, peciolo, gáster, coxas, fémures, tibias, tarsos y uñas tarsales amarillentos o hialinos; margen masticador de las mandíbulas marrón-rojizo. Los segmentos antenales algunas veces pueden ser marrón claro al igual que los últimos dos segmentos del gáster.

Medidas de la reina. $(n=6)$ : LC: $0,50-0,54$; AC: $0,50-0,52$; LE: 0,42-0,50; LW: 0,77-0,85; IE: 82-93; IC: 93-100.

Diagnosis de la reina. Escapos largos, alcanzando o sobrepasando el vértice posterior cefálico. 2do y 3er segmento de los palpos maxilares en forma de espátula (Figs. 2C-2D, 3C).

Descripción de la reina. Cabeza: Cápsula cefálica semitriangular, casi tan ancha como larga. En vista frontal, márgenes laterales de la cabeza convexos, margen occipital casi recto, a veces con una concavidad somera pero amplia en el vértex; esquinas postlaterales redondeadas. Mandíbulas semitriangulares, margen masticador armado con la siguiente dentición: diente apical espiniforme, más largo que ancho, diente subapical de menor tamaño que el apical, 3er diente $1 / 2$ más pequeño de la longitud del subapical, 4to diente un poco más grande que el 3 er diente, resto del margen masticador aserrado con dentículos que se extienden más allá del margen basal. En vista frontal, margen posteromedio del clípeo fuertemente arqueado extendiéndose entre el inicio de las carenas frontales; margen anterior del clípeo cóncavo, con una pequeña concavidad somera en el vértex. Antenas con 12 segmentos, escapos relativamente largos sobrepasando el límite posterior de la cabeza, con lados paralelos, ampliándose un poco hacia el ápice; pedicelo más largo que ancho, cuneiforme, ensanchándose hacia el 2do segmento, 2do segmento antenal cuadrado, más pequeño que el resto de los segmentos, 3ro-9no de forma rectangular, último segmento antenal tan largo como la suma del $7 \mathrm{mo}$ y $8 \mathrm{vo}$, con la punta redondeada. Ojos relativamente grandes, empezando en la máxima anchura de la cabeza y terminando en el declive de la anchura de los márgenes laterales de la cápsula cefálica, margen externo sobresaliente, rompiendo las líneas laterales de la cabeza.
Mesosoma: En vista lateral, pronoto pequeño, de forma casi rectangular; porción anterior del escudo redondeado, en vista dorsal, la porción posterior del escudo aplanada, margen anterior del escudo suavemente convexo y margen posterior recto; en vista dorsal, el escutelo se encuentra dividido del escudo por una línea marcada pero no profunda, escutelo de forma semitriangular a trapezoide con el margen anterior oblicuo en su mayor extensión, y margen posterior fuertemente convexo. Mesopleura dividida en dos segmentos, con el surco mesopleural recto y marcado: Anepisterno recto en la base y convexo en el extremo más distal, similar en forma a una herradura, katepisterno semicuadrado; metanoto estrecho, restringido a una pequeña banda dos veces más larga que ancha; en la misma vista, propodeo angosto, cara dorsal relativamente ancha, curvándose hacia atrás para continuarse en un declive relativamente largo; espiráculo propodeal circular, con un reborde marcado en forma de anillo, proyectando al espiráculo hacia afuera.

Metasoma: Pecíolo sin escama, completamente recto en su cara dorsal, lóbulo posteroventral prominente; gáster grande, de la misma longitud o más grande que la suma del mesosoma y la cabeza, cara dorsal aplanada, cara ventral convexa.

Superficie corporal y pilosidad: Superficie dorsal de la cabeza alveolada/reticulada, relativamente brillante, pilosidad amarillenta, recostada y espaciada de tal manera que la superficie queda visible. Superficie dorsal de la mandíbula cubierta de pelos largos, recostados y espaciados entre sí. Borde anterior del clípeo con dos setas centrales, relativamente largas, una a cada lado de la concavidad; superficie dorsal del clípeo cubierta de pequeña pilosidad amarillenta, corta y recostada. Escapos y segmentos antenales brillantes, tapizados con abundante pilosidad blanquecina, recostada y corta, pero espaciada; pelos semierectos sobresaliendo del contorno de los escapos, más notable en el quiebre de la inserción del pedicelo; segmentos con pilosidad corta semirecostada.

Mesosoma alveolado/reticulado, tagma brillante, tapizado con poca pilosidad amarillenta/blanquecina, muy corta y recostada, dejando ver claramente la superficie corporal, pilosidad notable en vista lateral sobre todo en el pronoto, sin setas en el mesosoma.

Metasoma cubierto también de pilosidad amarilla, fina, corta y espaciada, dejando ver la superficie. Superficie dorsal del peciolo desprovisto de pelos, superficie ventral con pilosidad relativamente corta amarillenta, semirecostada, dirigida hacia atrás, más notable en el lóbulo posteroventral, gáster tapizado con pilosidad amarillenta corta y recostada, porción distal del gáster con una configuración de ocho setas semierectas, cortas, pero sobresaliendo del contorno.

Coloración: hormigas por lo general bicoloreada, cápsula cefálica varia en tonalidad de marrón, a veces de color marrón oscuro opaco y otras veces marrón oscuro brillante, mandíbulas amarillentas con el margen masticador marrón-rojizo, clípeo generalmente bicoloreado, con porciones marrón oscuro y marrón-amarillento o en general amarillento, este último sobre todo en las porciones laterales, escapos y segmentos antenales amarillentos, por lo general, del mismo color de las mandíbulas. Mesosoma a veces bicoloreado, otras veces de color marrón oscuro, por lo general con manchas marrones en el pronoto, escudo, anepisterno, katepisterno, con las coxas y el resto de las patas color amarillento, peciolo completamente amarillento, gáster marrón oscuro, con bandas amarillentas en los márgenes posteriores. 
Distribución. En Colombia esta especie fue registrada anteriormente en zonas residenciales de los departamentos de Antioquia (Vergara-Navarro et al. 2007), Valle del Cauca (Olaya-Masmela et al. 2005; Chacón de Ulloa et al. 2006) y Chocó, en este último T. melanocephalum fue registrada en el bosque primario de Cabo Corrientes-Golfo Tribugá (Armbrecht et al. 2001). En este trabajo, se amplía la distribución geográfica en el país a los departamentos de Caldas, Cauca, Cundinamarca, Córdoba, Huila, Norte de Santander, Magdalena, Meta, Putumayo, Risaralda, San Andrés y Providencia, Santander, Sucre, Tolima y Vichada (Fig. 6B).

Biología. Algunos ejemplares de T. melanocephalum fueron recolectados en plantaciones de papaya, fragmentos de bosque secundario y sobre el suelo dentro de viviendas; también se obtuvieron muestras empleando trampas de cebo de panela. Otros registros mencionan a T. melanocephalum anidando en Ceiba pentandra (L.) Gaertn, árbol originario de la región tropical (Dick et al. 2007).

Material examinado. 2 obreras. COLOMBIA. Antioquia. Amalfi. Santa Lucia. Cañón del Porce. 650’16.62N $75^{\circ} 10^{\prime} 24.95 \mathrm{O}$. Winkler. Nov-2006. Vanegas, M. A. [MEFLG]. 1 obrera. Caucasia. $7^{\circ} 59^{\prime} 20^{\prime \prime} \mathrm{N} 75^{\circ} 11^{\prime} 56^{\prime \prime} \mathrm{O} .50 \mathrm{~m}$. Jun.2003. Pérez, M. y Pérez, F. [MEFLG]. 2 obreras. Medellín. Santa Elena. Vda. El Llano. 6 6 11'35.5N 75²9'50.6O. 2622 m. 22-oct-2011. Trampa de cebo. Sánchez-R, J. D. [CEUA]. 3 obreras. Medellín. 1566 m. Gallego, F. L. [MEFLG]. 4 obreras. Medellín. 1566 m. Nov-1995. Serna, F. [MEFLG]. 1 obrera. Caldas. Norcasia. Vda. San Roque. Reserva Natural Rio Manso. 5³9'40N 7446'98O. 160-220 m. Winkler. 6-8-ago-2004. González, E., Arango, L. y Montes, A. [IAvH-E]. 8 obreras. Cauca. Parque Nacional Natural Gorgona-PNNG. Send. La Chonta. $2^{\circ} 58^{\prime} 4.4 \mathrm{~N} 78^{\circ} 10^{\prime} 42.7 \mathrm{O}$. 35 m. Winkler. 26-28-feb-2011. Valdés, S. [MUSENUV]. 2 obreras. Córdoba. Montería. Buenos Aires. Fca. Villa Margarita. 50 m. 29-jun-2009. [CGIBEMH]. 2 obreras. Cundinamarca. La Vega. Vda. Tabacal. Reserva Laguna El Tabacal. $5^{\circ} 2^{\prime} 0.06 \mathrm{~N} 74^{\circ} 19^{\prime} 41.5 \mathrm{O}$. 1300-1450 m. Mini Winkler. 5-jul-2009. Perea-Acevedo, E. I. [MPUJ]. 3 obreras. Huila. Altamira. 1020 m. Recolecta manual. 8-dic-1974. Mackay, W. y Mackay, E. [CWEM]. 3 obreras. Altamira. 1020 m. Recolecta manual. 8-dic-1974. Mackay, W. [CWEM]. 3 obreras. La Vega. 764 m. Recolecta manual. 14-17-jul-1975. Mackay, W. [CWEM]. 2 reinas. Neiva. $508 \mathrm{~m}$. Recolecta manual. 20may-1975. Mackay, W. y Mackay, E. [MZUSP]. 1 obrera, 4 reinas. Neiva. 508 m. Recolecta manual. 20-may-1975. Mackay, W. y Mackay, E. [CWEM]. 3 obreras. Neiva. 508 m. Recolecta manual. 13-jul-1975. Mackay, W. [CWEM]. 1 obrera. 12Km S de Neiva. Recolecta manual. 2-ene-1984. Mackay, W. [CWEM]. 1 obrera. 8Km O de La Plata. Recolecta manual. 3-ene-1984. Mackay, W. [CWEM]. 3 obreras. 4Km E de Rivera. Recolecta manual. 30-dic-1986. Mackay, W. [CWEM]. 4 obreras. 4Km E de Rivera. Recolecta manual. 6-ene-1987. Mackay, W. [CWEM]. 10 obreras. Norte De Santander. Cúcuta. Recolecta manual. García, E. [CBUMAG]. 2 obreras, 4 reinas. Magdalena. Rio Frio. $10^{\circ} 54^{\prime} \mathrm{N} 74^{\circ} 10^{\prime} \mathrm{O}$. Recolecta manual. 14-ago-1985. Müller, H. G. [PSWC]. 1 obrera. Parque Nacional Natural Tayrona -PNNT. 15-jun-1976. Martínez, E. [IAvH-E]. 2 obreras. Parque Nacional Natural Tayrona -PNNT. Bahía Neguanje. $11^{\circ} 21^{\prime} \mathrm{N} 74^{\circ} 5^{\prime} \mathrm{O}$. Recolecta manual. 25-jun-1985. Müller, H. G. [PSWC]. 5 obreras. Parque Nacional Natural Tayrona -PNNT. Cañaveral - Cabo San
Juan del Guía. 0-50 m. 21-may-1977. Kugler, C. [IAvH-E]. 11 obreras. Parque Nacional Natural Tayrona -PNNT. Zaino. $11^{\circ} 20^{\prime} \mathrm{N} 74^{\circ} 2^{\prime}$ O. 50 m. Malaise. 28 -jun-2000. Henríquez, R. [IAvH-E]. 7 obreras. San Sebastián. El Guasimo. Fca. El Totumo. 32 m. 1-oct-2009. [CGIBEMH]. 1 obrera. Santa Marta. Bonda. Villa Culebra. $11^{\circ} 14^{\prime} \mathrm{N} 74^{\circ} 7^{\prime} \mathrm{O}$. Recolecta manual. Nov-dic-1985. Müller, H. G. [PSWC]. 1 obrera. Meta. La Esperanza. Lomalinda. [MPUJ]. 8 obreras. Putumayo. Villagarzón. 3-sep-1977. [IAvH-E]. 20 obreras. Risaralda. Apía. Vda. La Estrella. 1500 m. 11-ene-2002. [CGIBEMH]. 20 obreras. San Andrés, Providencia y Santa Catalina. San Andrés Isla. $12^{\circ} 32.245^{\prime} \mathrm{N} 81^{\circ} 42.660 .37$ m. 30-sep-2012. Silva-Gómez, M. [MEFLG]. 5 obreras, 1 reina. Santander. Bucaramanga. 960 m. 2-oct-1997. Acosta, A. E. [IAvH-E]. 1 reina. Sucre. San Benito Abad. Vda. Santiago Apóstol. Fca. Marbella. Sector La Caimanera. 9 ${ }^{\circ}$ ' $19 \mathrm{~N} 75^{\circ} 54^{\prime} 25 \mathrm{O} .30 \mathrm{~m}$. Winkler. 5-7-may-2009. Franco, L. E. [IAvH-E]. 2 obreras. Tolima. Méndez. Bosque El Cardonal. 252 m. 14-nov-1995. Fernández, F. [IAvH-E]. 3 obreras. Méndez. Hda. Cardonal. $5^{\circ} 5^{\prime} 38 \mathrm{~N} 75^{\circ} 46^{\prime} 4$ O. 300 m. [IAvH-E]. 5 obreras, 1 reina. Valle del Cauca. Buga. 789 m. Recolecta manual. 9-ene-1976. Mackay, W. y Mackay, E. [CWEM]. 6 obreras. Cali. 1000 m. Recolecta manual. 6-ene-1976. Mackay, W. y Mackay, E. [CWEM]. 20 obreras. Cali. Barrio Bolívar. 1000 m. 4-oct1999. Castaño, O. [CGIBEMH]. 11 obreras. Cali. Barrio Bolívar. $1000 \mathrm{~m}$. [CGIBEMH]. 20 obreras. Cartago. $3433 \mathrm{~m}$. [CGIBEMH]. 2 obreras, 2 reinas. Dagua. $1532 \mathrm{~m}$. Recolecta manual. 7-ene-1976. Mackay, W. y Mackay, E. [CWEM]. 1 obrera. La Cumbre. Vda. El Chicoral. $1850 \mathrm{~m}$. Recolecta manual. 5-may-2008. [CWEM]. 2 obreras. COLOMBIA. Vda.

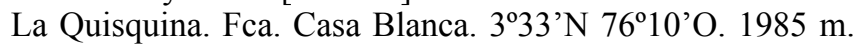
Winkler. Ago-2006. [CGIBEMH]. 1 obrera. Vichada. Parque Nacional Natural El Tuparro. Bosque Sabana. $5^{\circ} 21^{\prime} \mathrm{N}$ $67^{\circ} 51^{\prime}$ W. 100 m. Malaise. 29-nov-2000. Villalba, W. [IAvHE].

\section{Tapinoma ramulorum Emery, 1896 \\ (Figs. 4, 6C)}

Medidas de la obrera. $(\mathrm{n}=10)$ : LC: $0,50-0,60$; AC: $0,42-$ 0,56; LE: 0,40-0,63; LW: 0,50-0,67; IE: 75-110; IC: 85-97.

Diagnosis de la obrera. Obreras relativamente grandes (LW: 0,50-0,67); cabeza, mesosoma y metasoma completamente marrón oscuro a claro; patas coloreadas distintivamente, fémures marrones, trocánteres amarillentos, al igual que las tibias, tarsos y uñas tarsales. Ojos con más de ocho facetas en su máxima longitud (Figs. 4A-4D).

Descripción de la obrera. Cabeza: Cápsula cefálica semicuadrada, en vista frontal más larga que ancha, mayor amplitud de la cápsula a la altura o por encima de los ojos, casi a la mitad de la longitud de la cabeza; márgenes laterales convexos; margen occipital recto, a veces con una somera o marcada concavidad relativamente amplia en el vértex; esquinas posterolaterales redondeadas, continuándose sin interrupción hacia los márgenes laterales. Mandíbulas semitriangulares, con el margen externo recto en la porción medio-posterior y fuertemente curvado hacia la porción más apical de la mandíbula, margen masticador armado con la siguiente dentición: un diente apical triangular, más largo que ancho, diente subapical largo $1 / 4$ menos de la longitud del diente apical, 3 er diente triangular más pequeño que el anterior, 4to diente trian- 


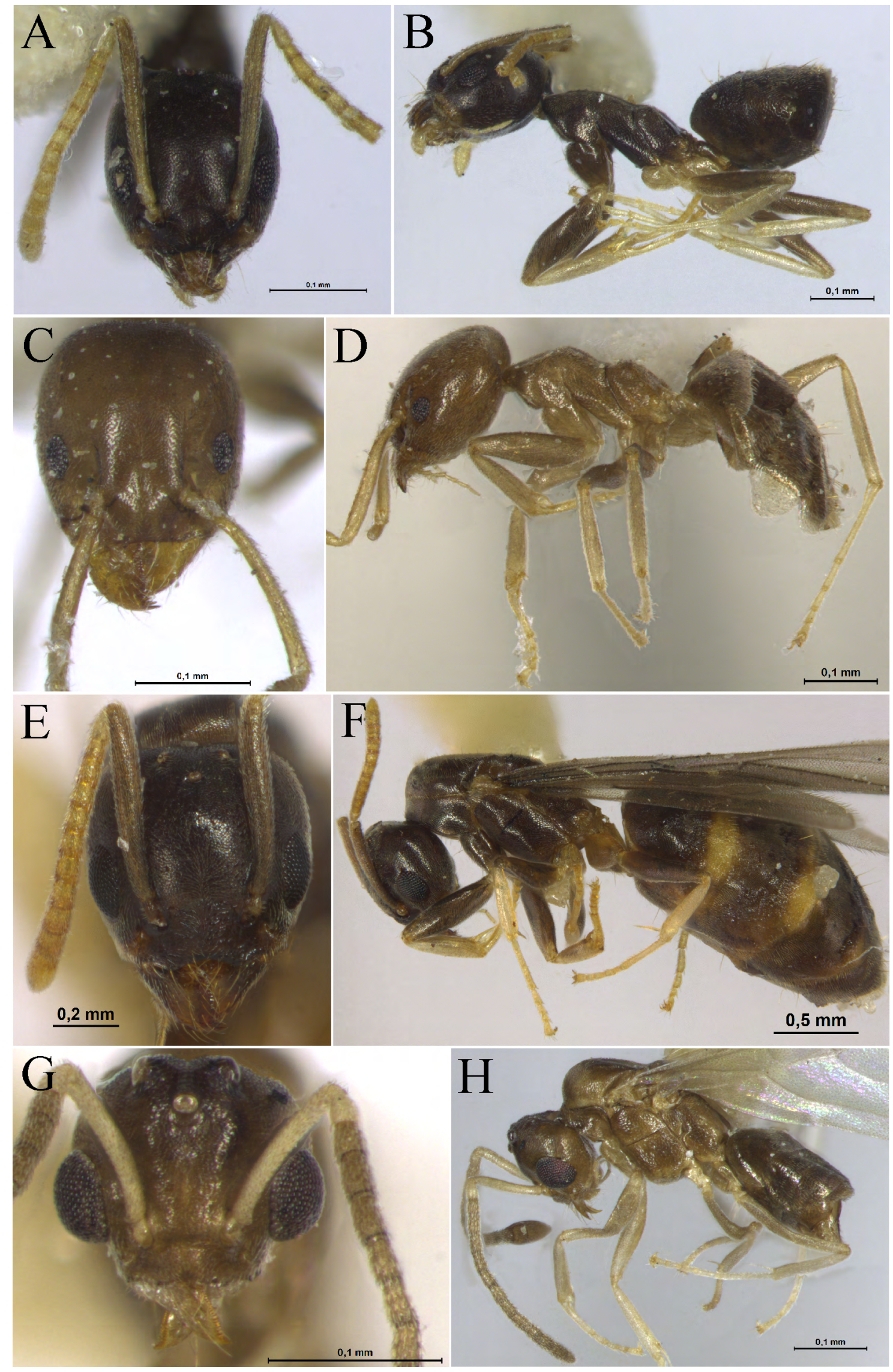

Figura 4. Hábito de T. ramulorum. A. Vista frontal de la cabeza de la obrera. B. Vista lateral de la obrera. C. Vista frontal de la cabeza de la obrera de Nariño. D. Vista lateral de la obrera de Nariño. E. Vista frontal de la cabeza de la reina. F. Vista lateral de la reina; G. Vista frontal de la cabeza del macho. H. Vista lateral del macho. 
gular similar en longitud y forma al subapical, puede o no haber un 5to diente similar en longitud y forma al 3er diente, seguido de dientes minúsculos que disminuyen en anchura y tamaño convirtiéndose en un margen aserrado que se extiende hasta el margen basal no diferenciado, tal margen no posee ángulo o esquina que lo limite, el borde aserrado se diluye de forma casi imperceptible hacia la inserción de la mandíbula. Palpos maxilares no alcanzan la mitad de la cara ventral de la cápsula cefálica, 2do segmento de los palpos maxilares largo, cuneiforme, 2do segmento en forma de barril, más pequeño que el resto de segmentos, 4to segmento largo, pero más corto que el 2 do segmento. En vista dorsal, margen anterior del clípeo a veces con concavidad amplia, relativamente somera, con esquinas redondeadas continuándose hacia los márgenes laterales del clípeo, estos últimos relativamente rectos a sinuosos; vértice del margen posterior clipeal fuertemente convexo, proyectándose apenas entre las bases de las inserciones antenales. Antenas con 12 segmentos, escapos antenales con lados paralelos, algunas veces ensanchándose hacia el ápice, de longitud variable, sin embargo, siempre sobrepasando el margen occipital por más de $1 / 4$ de la longitud total del escapo; primer segmento o pedicelo cuneiforme, más largo que ancho, 2do segmento antenal pequeño en forma de barril, 3er8 vo segmento rectangular, 9no segmento cuadrado, último segmento tan largo como la suma de los dos segmentos que le preceden, más ancho que el resto de segmentos antenales, semejando una maza antenal. Ojos grandes con más de ocho facetas, ubicados anteriormente, por debajo de la mitad de la mayor longitud de la cabeza, a la altura o un poco por debajo del máximo ancho de la cabeza.

Mesosoma: En perfil, sutura promesonotal convexa; hombros pronotales proyectados hacia afuera; surco metanotal marcado en una línea fina similar a una incisión, no profunda. Pronoto en vista dorsal trapezoidal, más ancho que largo, cara anterior más ancha que la cara posterior; en la misma vista mesonoto rectangular, más ancho que largo; propodeo con cara dorsal corta, angulada en la parte más posterior, cayendo en un declive relativamente largo y recto, sobrepasando en tres veces la cara dorsal; espiráculo propodeal visible, circular, puede estar ubicado por encima o un poco más debajo de la mitad de la línea del declive.

Metasoma: Peciolo sin escama, cara dorsal recta, cara anterior ventral recta, lóbulo posteroventral prominente, proyectándose desde la mitad de la cara ventral. Primer tergo más ancho que largo, notablemente más ancho que el resto de los tergos del gáster.

Superficie corporal y pilosidad: Cápsula cefálica vista de frente reticulada/alveolada, brillante, tapizada de pilosidad amarilla muy corta. Superficie dorsal de la mandíbula brillante, con pelos amarillentos largos semierectos, separados entre sí a una distancia que dejan ver la coloración de la mandíbula, pelos más largos hacia el borde masticador y más cortos hacia el margen externo y en la parte más posterior de la mandíbula cercana a la inserción de las mandíbulas al clípeo. Superficie dorsal del clípeo tapizado con pilosidad amarilla corta, recostada, a veces con abundantes pelos cortos en la porción central del clípeo, desde el margen anterior hasta el borde posterior; reborde anterior del clípeo con un par de setas largas, ubicadas en cada esquina curva de la muesca clipeal, cada una reposando en una fóvea conspicua, a veces más oscura que la coloración del clípeo, el resto del reborde anteroclipeal una fila de pelos cortos y largos curvos hacia adentro. Escapos relativamente opacos, cubiertos con pilo- sidad muy corta, amarillenta, recostada y espaciada entre sí de tal manera que se ve la superficie del segmento antenal; contornos de los escapos cubiertos de pelos semirecostados, dirigidos hacia arriba, aumentando en longitud hacia el ápice distal; resto de segmentos antenales cubiertos de abundante pilosidad corta, amarillenta y semirecostada.

Mesosoma en vista dorsal, densamente cubierto de pequeñas puntuaciones, mesopleura sin división aparente entre anepisterno y katepisterno, brillante y reticulada. Tagma cubierto de fina pilosidad, muy corta, recostada sobre la superficie del cuerpo; mesopleura y metapleura con pilosidad más larga y más separada que en la porción dorsal del tagma. Coxas con pilosidad amarillenta, corta, patas cubiertas de densa pilosidad, corta, amarillenta y separada entre sí.

Peciolo con la cara dorsal lisa y brillante, cara ventral con pilosidad en la porción más anterior y en el lóbulo posteroventral pelos gruesos, semirecostados, dirigidos hacia atrás, relativamente largos. Gáster tapizado de abundante pilosidad amarillenta, relativamente larga y gruesa.

Coloración: Hormigas generalmente marrón oscuro a claro en todo el cuerpo, con segmentos antenales, coxas, tibias, tarsos, uñas tarsales y peciolo amarillento; los escapos pueden variar en color de marrón oscuro a amarillentos. Mandíbula generalmente marrón claro, margen masticador marrónrojizo.

Medidas de la reina. $(\mathrm{n}=1)$ : LC: 0,65 ; AC: 0,65 ; LE: 0,62 ; LW: 1,15; IE: 94; IC: 100.

Diagnosis de la reina. Escapos largos, sobrepasando el límite posterior de la cabeza por una longitud mayor a la suma del pedicelo más el segundo segmento antenal; vértice posterior cefálico con una somera concavidad amplia. Patrón de coloración como el de la obrera, con cabeza, mesosoma y metasoma marrón oscuro a claro; patas coloreadas distintivamente, fémures marrones, trocánteres amarillentos, al igual que las tibias, tarsos y uñas tarsales (Figs. 4E-4F).

Descripción de la reina. Cabeza: Cápsula cefálica semicuadrada a semitriangular, tan larga como ancha. En vista frontal, lados de la cabeza convexos, margen occipital recto, vértex con concavidad somera pero amplia. Mandíbulas semitriangulares, margen masticador armado con la siguiente dentición: diente apical triangular, más largo que ancho, diente subapical de menor tamaño que el apical, 3er diente más pequeño que la longitud del diente apical, 4to diente de mayor longitud que el 3er diente, 5to diente un poco más pequeño que el $3 \mathrm{er}$ diente, resto del margen masticador aserrado con dentículos romos y densos que se extienden más allá del margen basal, este último sin ángulo que lo diferencie. En vista frontal margen postero-medio del clípeo ampliamente excavado, concavidad relativamente profunda, sin embargo, la concavidad se extiende apenas entre las inserciones antenales; margen anterior del clípeo con porción central ampliamente cóncava y profunda, márgenes anterolaterales del clípeo rectos. Escapos de las antenas relativamente largos, generalmente alcanzando y sobrepasando el margen posterior de la cabeza por una longitud mayor a la suma del pedicelo y el 2do segmento antenal; pedicelo cuneiforme, más largo que ancho, 2do segmento semicuadrado, 3er-8vo rectangular o en forma de barril, $7 \mathrm{mo} \mathrm{y} 8$ vo más anchos que los que les preceden, último segmento antenal con punta redondeada, más largo que ancho, los tres últimos segmentos antenales for- 
man como una maza. Ojos grandes, ubicados por debajo del máximo ancho de la cabeza, en vista frontal, margen externo sobresaliente rompiendo los márgenes laterales de la cabeza.

Mesosoma: En vista lateral, pronoto semicuadrado, relativamente ancho; en la misma vista, porción anterior del escudo redondeado, en vista dorsal, porción dorsal del escudo aplanada; margen anterior del escudo fuertemente convexo y margen posterior recto a veces sinuoso; escudete semitriangular a trapezoide, separado del escudo por una banda marcada $\mathrm{y}$ poco profunda, margen anterior fuertemente oblicuo y margen posterior con el ápice redondeado; mesopleura dividida en dos segmentos, con el surco mesopleural recto marcado: anepisterno recto en el margen posterior y el margen anterior fuertemente convexo, semejante a una herradura, katepisterno rectangular; en vista dorsal, metanoto estrecho, restringido a una pequeña banda dos veces más larga que ancha. En vista de perfil, propodeo ancho, muy por debajo del mesonoto, mostrando cara dorsal angosta, curvándose posteriormente hacia atrás para continuarse en un declive relativamente largo; espiráculo propodeal circular, ubicado donde empieza el declive propodeal, con reborde pronunciado proyectándolo hacia afuera, abriéndose entre el declive del propodeo y la cara dorsal.

Metasoma: Peciolo sin escama, recto en la cara dorsal, lóbulo posteroventral prominente, desarrollado. Gáster bastante grande, casi dos veces su longitud de Weber. Cara dorsal fuertemente oblicua, cara ventral cóncava.

Superficie corporal y pilosidad: Cápsula cefálica vista de frente alveolada, con puntuaciones finas, relativamente brillante; cubierta de pilosidad amarillenta/blanquecina, notándose más en la porción del clípeo y de las genas, recostada y espaciada de manera que se puede ver la superficie de la cabeza. Superficie dorsal de la mandíbula cubierta de pelos relativamente largos, recostados y espaciados entre sí, quedando visible la superficie relativamente brillante; los pelos semierectos y más largos cerca al borde masticador y al margen externo. Superficie dorsal del clípeo cubierta de pilosidad amarillenta o corta, semi-recostada. Borde anterior del clípeo con un par de setas centrales, una a cada lado de la concavidad, relativamente largas, cada una reposando en una fóvea, a veces más oscura que la coloración del clípeo, el resto del margen anterior tapizado de pelos cortos amarillentos, recostados y curvados hacia las mandíbulas. Escapos tapizados de abundante pilosidad amarillenta, corta, semierecta y espaciada, se puede observar pelos semierectos sobresaliendo del contorno de los escapos; segmentos antenales con pelos cortos, semierectos, sobresaliendo del contorno de los segmentos.

Mesosoma relativamente brillante, cubierto de puntuaciones finas, superficie fuertemente reticulada, mucho más notable en vista lateral del tagma, tapizado con abundante pilosidad amarillenta, corta, recostada y espaciada dejando ver la superficie, pilosidad notable en la misma vista; en vista de perfil la pilosidad del escudo es más larga, dando forma a la superficie reticulada, cinco o más setas erectas en el escudo, cinco o más setas erectas en el escutelo.

Metasoma cubierto completamente de pilosidad amarillenta, corta, relativamente recostada y bastante separada dejando ver la superficie, pilosidad más notable en la porción ventral del tagma, superficie alveolada/reticulada. Cara dorsal del peciolo lisa, lóbulo posteroventral con pelos relativamente largos, semirecostados y dirigidos hacia atrás. Porción distal del 4 esterno con pelos semierectos, cortas, curvadas hacia atrás y sobresaliendo del contorno.
Coloración: Hormigas por lo generalmente marrón oscuro a claro en todo el cuerpo. Cápsula cefálico marrón oscuro, mandíbula marrón claro a oscuro con el margen masticador marrón-rojizo; segmentos antenales y escapos de marrón a amarillento opaco más claro que las mandíbulas; mesosoma y fémures de tonalidad marrón oscuro, con coxas, tarsos, uñas tarsales amarillentos, peciolo totalmente amarillento; gáster tan oscuro como el mesosoma, con bandas amarillentas en los márgenes posteriores.

Medidas del macho. $(\mathrm{n}=3)$ : LC: 0,40; AC: 0,40-0,42; LE: 0,35-0,38; LW: 0,69-0,77; IE: 86-95; IC: 100-105.

Diagnosis del macho. Hormigas pequeñas (LW: 0,69$0,77)$, con la cabeza semi-triangular y escapos sobrepasando el límite posterior de la cabeza. Ojos compuestos extremadamente grandes, globosos, sobresaliendo del margen lateral de la cabeza, ocelos protuberantes interrumpiendo el margen occipital y sobresaliendo de la superficie de la cabeza. Propodeo completamente inclinado sin cara dorsal recta (Figs. 4G-4H).

Descripción del macho. Cabeza: Cápsula cefálica en vista frontal, globosa, semitriangular, casi tan larga como ancha; margen occipital fuertemente convexo, interrumpido por la protuberancia de $2 / 3$ ocelos, creando una concavidad en el vértex; márgenes posterolaterales redondeados, continuándose hacia los márgenes laterales interrumpidos por el contorno externo de los ojos. Mandíbulas delgadas, semitriangulares, más largas que anchas, cruzándose entre sí al estar cerrada; con los márgenes externos rectos hacia la base y curvados hacia el extremo más distal, margen masticador con un diente apical, más largo que ancho, espiniforme, continuado por cinco dentículos $3 / 4$ más pequeños que el diente apical, seguidos por un margen aserrado compuestos de dentículos, romos, muy juntos entre si hasta el margen basal indiferenciado. Palpos maxilares sobrepasando la mitad de la cabeza; margen anteromedio del clípeo con concavidad somera, márgenes laterales cóncavos hacia el centro del vértex, formando esquinas o ángulos con la depresión media; margen posterior en el vértice convexo, apenas sobre las bases de las inserciones antenales. Fosas antenales con reborde pronunciado y grueso, en forma de anillo; carenas frontales rectas, un poco transversas y profundas, región intercarenal relativamente amplia. Escapos antenales largos, sobrepasando el margen posterior cefálico por una longitud mayor al pedicelo de la antenal; este último cuneiforme, 2do-11vo segmentos antenales semi-rectangulares, todos similares en tamaño y forma, último segmento casi dos veces el largo que el anterior, con el extremo distal redondeado. Ojos compuestos bastante grandes, globosos, ubicados debajo de la máxima anchura de la cabeza. Ocelos notablemente grandes, prominentes, sobresalen por encima de la superficie y quiebran el margen posterior de la cabeza.

Mesosoma: En vista de perfil, pronoto relativamente ancho; en la misma vista porción anterior del escudo globoso, alto, sobresaliendo por encima del propodeo, en vista dorsal, escudo trapezoidal con el margen anterior ancho y convexo, márgenes laterales rectos, transversos, a veces con concavidad somera cerca de las inserciones de las alas, margen posterior fuertemente oblicuo, formando ángulos definidos donde se encuentra con los márgenes laterales; escutelo semitriangular, con el margen anterior convexo, márgenes laterales 
rectos y transversos convergiendo hacia el margen posterior, este último cóncavo; mesopleura dividida en dos: anepisterno en forma de herradura a semitriangular; katepisterno semicuadrado, con los márgenes laterales paralelos. Metanoto restringido a una banda estrecha, más larga que ancha, oblicua. Propodeo muy por debajo del mesonoto, en vista lateral, declive propodeal largo; espiráculo propodeal ovalado, grande, ubicado en la mitad de la longitud del declive, abriéndose sin tocar el margen recto del declive.

Metasoma: Cara dorsal del peciolo recta, sin escama peciolar; lóbulo posteroventral pronunciado, ocupando la mitad de la longitud del peciolo. Gáster con cara dorsal convexa y cara ventral cóncava.

Superficie y pilosidad: Cápsula cefálica fuertemente alveolada, brillante solamente en los ocelos protuberantes, cubierta de pelos amarillentos/blanquecinos, muy cortos y recostados, espaciados dejando ver la superficie de la cabeza. Mandíbulas con poca pilosidad, pero larga, semirecostada y muy espaciada dejando ver la superficie brillante. Placa clipeal tapizada de pilosidad relativamente corta, pelos de mayor longitud ubicados en la porción central del clípeo y dirigidos hacia el centro; margen anterior clipeal con un par de setas largas ubicadas en cada una de las esquinas de la concavidad, seguidas de pelos curvos hacia adentro del margen. Escapos antenales relativamente opacos, cubiertos de pilosidad amarillenta, cortos, espaciados y semirecostados, sobresaliendo en el ápice del segmento antenal; segmentos antenales tapizados de abundantes pelos amarillentos, cortos, decumbentes, gruesos y distanciados entre sí.

Superficie del mesosoma brillante sobre todo en la meso y metapleura, cubierta de alveolos conspicuos sobre todo en el katepisterno y anepisterno; pilosidad blanquecina corta y espaciada más notable en vista lateral de la porción anterior del declive del propodeo; patas cubiertas de pelos amarillentos cortos, recostados y espaciados, dejando ver la superficie de los apéndices.

Peciolo brillante, con pelos en la parte posterior de la superficie ventral; superficie del gáster cubierta de pilosidad blanquecina, corta y recostada, formando reticulaciones, separa entre sí de tal manera que dejan ver la superficie de los escleritos; en vista ventral 1er esterno con mechón de pelos largos y gruesos, con fóveas notables. Telómeros con abundantes pelos relativamente largos, concentrados en el ápice.

Coloración: Hormigas color marrón, con mandíbulas, escapos, tibias, tarsos, uñas tarsales de tonalidad más clara. Cápsula cefálica y segmentos antenales marrón oscuro, mandíbula marrón claro a amarillo pálido, con el margen masticador marrón-rojizo; clípeo marrón, un poco más claro que el resto de la cabeza. Mesosoma marrón ligeramente más claro que la cabeza; fémur de todas las patas, marrón oscuro hacia la base. Metasoma marrón tan oscuro como la cabeza.

Distribución. Se registra a T. ramulorum en los departamentos de Antioquia, Cauca, Cundinamarca, Meta, Nariño, Quindío, Risaralda, Sucre y Valle del Cauca, con la mayoría de registros en la región andina colombiana (Fig. 6C).

Biología. Se encontraron poblaciones de T. ramulorum en un intervalo de altitud de 60 a $1.845 \mathrm{msnm}$, registrándose la menor altitud en el Parque Nacional Natural Gorgona (Dpto. Cauca) y la mayor en el municipio de Apia (Dpto. Risaral- da). Además, las hormigas fueron recolectadas con diferentes métodos de muestreo (manual, Winkler, Malaise y golpeteo), sugiriendo hábitats variables; otros especímenes fueron colectadas en rastrojo de Vismia Vand., 1788 y en Cattleya Lindl., 1824.

Material examinado. 1 obrera. COLOMBIA. Antioquia. Amalfi, Santa Lucia. Winkler. 30-jul-1997. Serna, F. [MEFLG]. 1 obrera. Amalfi, Santa Lucia. 9-oct-1997. Serna, F. [MEFLG]. 9 obreras. Amalfi. Santa Lucia. $6^{\circ} 46.316^{\prime} \mathrm{N}$ 75⒌442'O. 30-jun-1998. Serna, F. [MEFLG]. 3 obreras. Cauca. Parque Nacional Natural Gorgona -PNNG. Alto El Mirador. $2^{\circ} 58^{\prime} \mathrm{N} 78^{\circ} 11^{\prime}$ O. 180 m. Malaise. 10-jun-2000. Torres, H. [IAvH-E]. 1 obrera, 1 reina, 9 machos. Parque Nacional Natural Gorgona-PNNG. Alto El Mirador. $2^{\circ} 58^{\prime} \mathrm{N}$ $78^{\circ} 11^{\prime}$ O. 180 m. Malaise. 6-20-nov-2000. Duque, R. [IAvHE]. 5 obreras. Parque Nacional Natural Gorgona-PNNG. El Roble. $2^{\circ} 58^{\prime} \mathrm{N} 78^{\circ} 11^{\prime} \mathrm{O} .130 \mathrm{~m}$. Malaise. 13-abr-7-may-2001. Torres, H. [IAvH-E]. 1 obrera. Parque Nacional Natural Gorgona -PNNG. Mancora. $2^{\circ} 58^{\prime} \mathrm{N} 78^{\circ} 11^{\prime} \mathrm{O}$. $60 \mathrm{~m}$. Malaise. 5-20-sep-2000. Torres, H. [IAvH-E]. 8 obreras, 1 reina, 3 machos. Cundinamarca. Pandi. Vda. Santa Elena. 1300 m. Recolecta manual. 18-mar-1978. Restrepo, R. [ICN]. 5 obreras. Meta. Borde entre el departamento del Meta y Cundinamarca. Recolecta manual, 28-dic-1975. Mackay, W. [CWEM]. 1 obrera. Parque Nacional Natural Sierra de la Macarena. Casino. $3^{\circ} 21^{\prime} \mathrm{N} 73^{\circ} 56^{\prime} \mathrm{W} .120 \mathrm{~m}$. Malaise. 29-oct-2003. Villalba, W. [IAvH-E]. 2 obreras. Parque Nacional Natural Sierra de la Macarena. Vda. Caño Curía. $3^{\circ} 21^{\prime} \mathrm{N} 72^{\circ} 38^{\prime} \mathrm{O} .100 \mathrm{~m}$. Malaise. 31-ago-12-oct-2003. Villalba, W. [IAvH-E]. 1 obrera. Parque Nacional Natural Sumapaz -PNNS. Cabañas Las Mirlas. $3^{\circ} 48^{\prime} \mathrm{N} 73^{\circ} 52^{\prime} \mathrm{O} .735 \mathrm{~m}$. Malaise, 5-sep-2003. Vargas, H. y Torrijos, A. [IAvH-E]. 1 obrera. Parque Nacional Natural Sumapaz -PNNS. Caño Curía. $3^{\circ} 21^{\prime} N$ 735'ㅇ․ 460 m. Malaise. 10-nov-2002. Duarte, M. [IAvH-E]. 2 obreras. Parque Nacional Natural Sumapaz -PNNS. Qda. La Cristalina. $3^{\circ} 48^{\prime} \mathrm{N} 73^{\circ} 50^{\prime} \mathrm{O} .614 \mathrm{~m}$. Malaise. 13-may-2004. Torrijos, A. [IAvH-E]. 2 obreras. Nariño. Barbacoas. Reserva Natural El Pangán. 1 ${ }^{\circ} 21^{\prime} \mathrm{N} 78^{\circ} 5^{\prime} 24^{\prime \prime} \mathrm{O} .671 \mathrm{~m}$. Recolecta manual. 27jul-2006. Miranda, A. y Reyes, O. [IAvH-E]. 6 obreras. Barbacoas. Reserva Natural El Pangán. 1'21'49”N 784'45”O. 640 m. Recolecta manual. 27-jul-2006. Miranda, A. y Reyes, O. [IAvH-E]. 1 obrera. Quindío. Genova. Vda. El Cedral. 4'22'36”'N 7546'10”'O. 1600 m. Golpeteo. 28-oct-1999. González, E. [IAvH-E]. 2 obreras. Genova. Vda. El Cedral. $4^{\circ} 14^{\prime} 6^{\prime \prime N} 75^{\circ} 46^{\prime} 32^{\prime \prime} O .1600$ m. Recolecta manual. 31-oct1999. González, E. [IAvH-E]. 1 obrera. Genova. Vda. El Do-

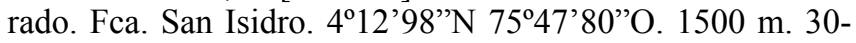
oct-1999. González, E. [IAvH-E]. 1 obrera. Risaralda. Apia. Monteverde. $5^{\circ} 8^{\prime} \mathrm{N} 75^{\circ} 57^{\prime} \mathrm{W} .1845$ m. 1-feb-2002. Armbrecht, I. [IAvH-E]. 1 obrera. Sucre. Colosó. Estación primatológica. Montes de María Sector La Cascada. 9³2'46”N $75^{\circ} 20^{\prime} 40^{\prime}$ O. 230 m. Recolecta manual. 29-abr-2009. Franco, L. E. [IAvH-E]. 1 obrera. Valle del Cauca. Parque Nacional Natural los Farallones de Cali. Anchicaya. 326'N 76² $48^{\prime} \mathrm{O}$. Malaise. 14-28-ago-2001. Sarria, S. [IAvH-E].

\section{Tapinoma sp.}

(Figs. 5, 6A)

Medidas de la obrera. $(n=4)$ : LC: $0,50-0,51 \mathrm{~mm}$; AC: $0,45-$ 0,48 mm; LE: 0,36-0,40 mm; LW: 0,36-0,50 mm; IE: 71-77; IC: 87-97. IE: 81-103. 


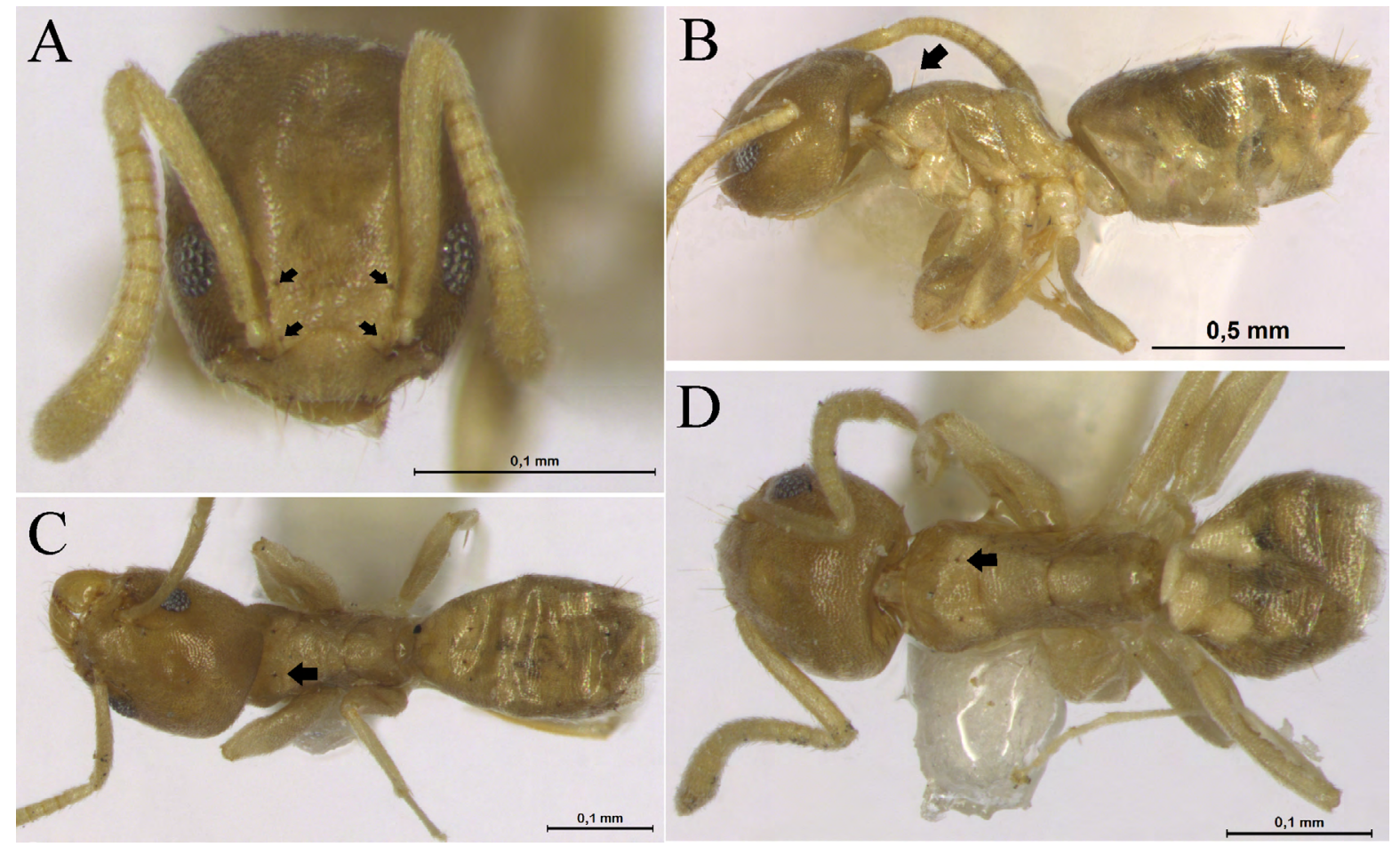

Figura 5. Hábito de Tapinoma sp. A. Vista frontal de la cabeza de la obrera. B. Vista lateral la obrera. C. y D. Vista dorsal. Las flechas indican los pelos erectos entre las carenas frontales y el dorso del pronoto.

Diagnosis de la obrera. Hormigas relativamente pequeñas (LW: 0,36-0,50), de color generalmente amarillento, superficie opaca, con escapos cortos que apenas alcanzan el limite posterior de la cápsula cefálica. Dos pares de pelos entre las carenas frontales, un par inferior y el otro superior; pronoto con dos pelos erectos en la superficie dorsal, ojos circulares, con seis facetas en su máxima longitud (Fig. 5).

Distribución. Se registra para cuatro departamentos: Antioquia, Huila, Magdalena y Meta. En el departamento del Magdalena se encontraron poblaciones distanciadas entre sí por algunos pocos kilómetros, habitando a $30 \mathrm{msnm}$ en el sector de Palangana-PNN Tayrona y a $225 \mathrm{msnm}$ en Pueblito-PNN Tayrona (Fig. 6A).

Biología. Recolectada mediante los métodos de captura manual y Malaise. Estas hormigas habitan en ramas secas y en el suelo del bosque seco al norte del país, y en ambientes abiertos en el Meta. También habita bosques montanos a más de $2.100 \mathrm{msnm}$ en Antioquia.

Comentario. Esta morfo-especie de Tapinoma es distinta a cualquier otra especie en Colombia, ya que es la única que presenta pelos erectos tanto en el pronoto como entre las carenas frontales. Las obreras son parecidas a $T$. litorale pero las de Tapinoma sp son más pequeñas y con escapos mucho más cortos (IE: 71-77) mientras que los escapos de las obreras de T. litorale son relativamente más largos (IE: 81-103). Más información sobre la morfología, distribución y los reproductores se incluirán en la revisión del género Tapinoma para la región Neotropical (Guerrero en preparación).

Material examinado. 3 obreras. COLOMBIA. Antioquia. El Santuario. 2165 m. 9-nov-1995. [MEFLG]. 6 obreras.
Huila. Rivera. 707 m. Recolecta manual. Mackay, W. y Mackay, E. [CWEM]. 2 obreras. 4Km S de Tello. Recolecta manual. 10-jun-1985. Mackay, W. y Mackay, E. [CWEM]. 1 obrera. Magdalena. Parque Nacional Natural Tayrona PNNT. Palangana. $11^{\circ} 20^{\prime} \mathrm{N} 74^{\circ} 2^{\prime} \mathrm{O} .30 \mathrm{~m}$. Malaise. 16-dic2000. Henríquez, R. [IAvH-E]. 1 obrera. Parque Nacional Natural Tayrona -PNNT. Pueblito. $11^{\circ} 20^{\prime} \mathrm{N} 74^{\circ} 2^{\prime}$ 'O. $225 \mathrm{~m}$. Malaise. 14-29-jul-2000. Henríquez, R. [IAvH-E]. 1 obrera. Meta. Parque Nacional Natural Sierra de la Macarena. Caño Curia. $3^{\circ} 21^{\prime} \mathrm{N} 72^{\circ} 33^{\prime} \mathrm{O} .493 \mathrm{~m}$. Malaise. 30-nov-2004. Villalba, W. [AvH-E].

\section{Discusión}

Tapinoma es un género de amplia distribución y bastante diverso en la región Neotropical (Guerrero, en preparación). Fernández y Sendoya (2004) registran 11 especies del género distribuidas en la región Neotropical, de las cuales sólo T. melanocephalum se registra para Colombia, ubicando a Brasil, con cinco especies, como el país más rico en especies de Tapinoma. Los resultados de esta revisión incrementan a cuatro el número de especies para Colombia: T. litorale, T. ramulorum, T. melanocephalum y Tapinoma sp.

Las poblaciones de T. litorale están restringidas al Caribe, tanto en regiones continentales como insulares (Wetterer y Guerrero 2017), esto explica el hecho de registrar poblaciones de esta especie en zonas insulares como San Andrés, Providencia y Santa Catalina, y en áreas de influencia caribeña como el PNN Tayrona en Santa Marta, Magdalena (Fig. 6A); sin embargo, algunos registros en el departamento del Cesar se alejan de la tendencia de distribución caribeña de esta especie (Fig. 6A). Así mismo, se encontró que exhibe una distribución altitudinal disyunta, con poblaciones que habitan en el bosque seco tropical en altitudes bajas al nivel del mar, 
dentro del PNN Tayrona, y otras poblaciones en el bosque montano bajo entre los 1.300-1.650 msnm, en la Sierra Nevada de Santa Marta. En las tierras bajas T. litorale puede encontrarse en simpatría con Tapinoma sp., aunque esta última posee una distribución geográfica más amplia, con mayores registros en la parte central del país (Fig. 6A) que alcanzan altitudes por encima de los $2.100 \mathrm{~m}$.

Tapinoma litorale se diferencia de Tapinoma sp. en que la primera no presenta pelos entre las carenas frontales ni en el pronoto (Figs. 1 y 5 , respectivamente), además las obreras de Tapinoma sp. son mucho más pequeñas que las obreras de $T$. litorale y uniformemente marrón amarillento, con la superficie opaca, mientras que las obreras de T. litorale son completamente amarillentas y algunas de color marrón claro, pero no como en la primera especie. Por otra parte, las dos especies también difieren en la longitud de los escapos, T. litorale (LE: 0,40-0,47) exhibe escapos de longitud varia- ble, mientras que en Tapinoma sp. (LE: 0,36-0,40) son más cortos, con algunos individuos con el ápice por debajo del vértice posterior cefálico, que apenas alcanzan las esquinas posterolaterales de la cápsula cefálica (Fig. 5A).

En Colombia, hasta la presente, la hormiga fantasma $T$. melanocephalum se registraba sólo para tres departamentos, con distribución restringida hacia la región andina y pacífica. En este estudio, se encontraron poblaciones en 17 departamentos más, mostrando una amplia distribución en todas las regiones del país (Fig. 6B); además, T. melanocephalum fue Recolectada con diferentes métodos de captura, lo que sugiere el aprovechamiento de diferentes tipos de hábitats, aspecto biológico explorado por Nickerson y Bloomcamp (1988), quienes sugieren que esta especie posee hábitos de anidación altamente adaptables, por lo que puede anidar al aire libre o en interiores, conllevando a que se pueda adecuar a diferentes ambientes y condiciones ecológicas (Smith 1965), facilitan-

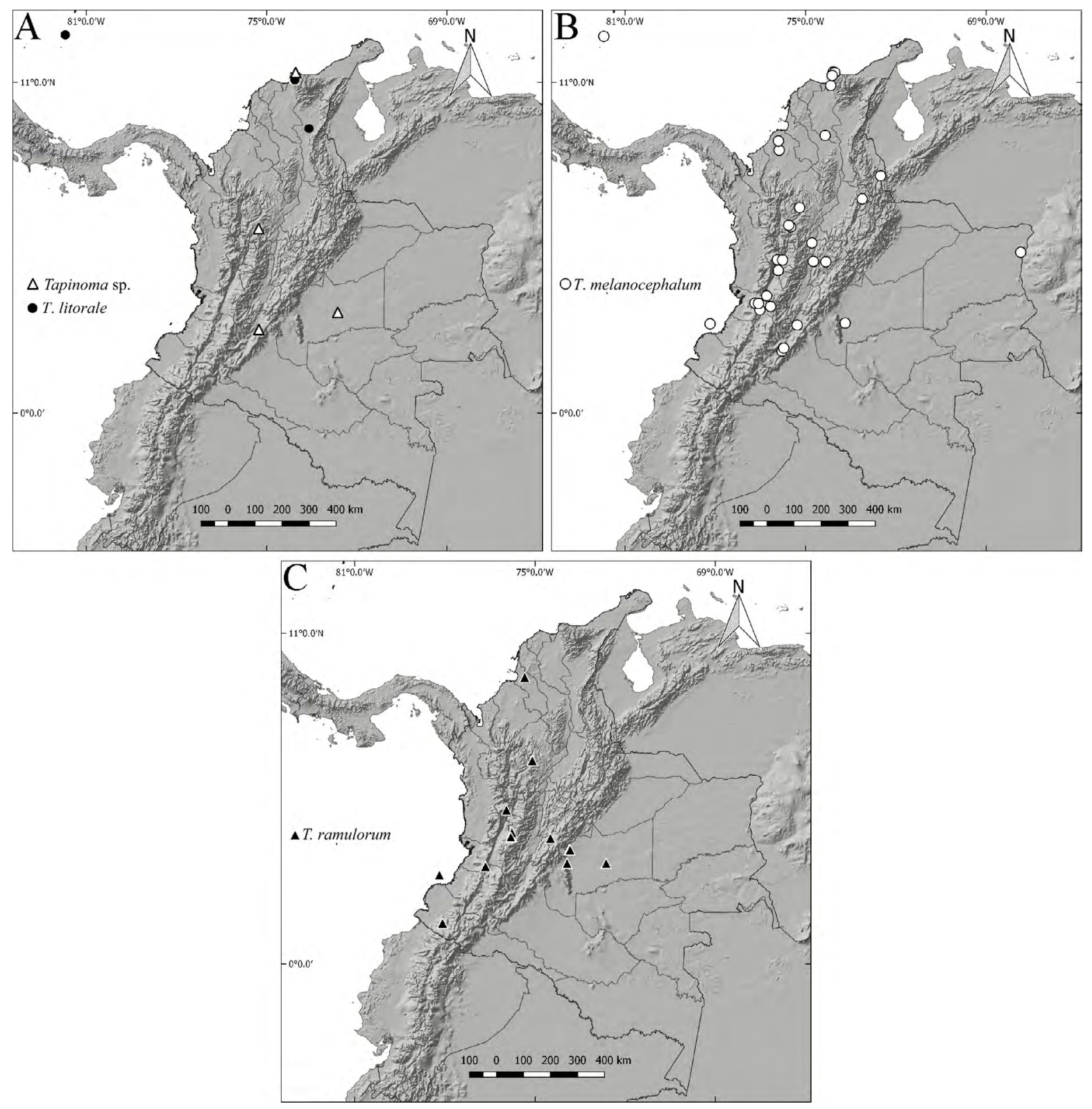

Figura 6. Distribución de las especies de Tapinoma en Colombia. A. Distribución de T. litorale y Tapinoma sp. B. Distribución de T. melanocephalum. C. Distribución de T. ramulorum. 
do así su capacidad de dispersión en casi todas las zonas del planeta, principalmente tropicales y subtropicales (Wetterer 2009). Por otra parte, las obreras de T. melanocephalum exhiben variación en la forma del 3er y 4to segmento de los palpos maxilares, los cuales pueden estar ensanchados en forma de espátula (Fig. 3A), o alargados o semicilíndricos (Fig. 3B), sin embargo, este carácter en la casta femenina no exhibe polimorfismo, manteniendo los segmentos de los palpos maxilares ensanchados y aplanados (Fig. 3C), siendo este un estado del caracter diagnóstico para la especie (Guerrero 2018).

Tapinoma ramulorum, registrada por primera vez para Colombia, exhibe una distribución principalmente Andina, con pocos registros para la región Caribe, en el departamento de Sucre. En esta especie se encontraron poblaciones con dos tipos de morfología relativamente contrastante en caracteres como la coloración, la longitud de los escapos y la forma de la cabeza. La morfología de las obreras de Cundinamarca y Sucre coincide con la descripción original de Emery (1896), lados de la cápsula cefálica convexos, margen posterior con somera depresión en el vértex y escapos largos, sobrepasando el limite posterior cefálico por una longitud igual a la suma del pedicelo y el segundo segmento antenal (Figs. 4A-4B); así mismo, las poblaciones de Cundinamarca exhiben un color marrón oscuro, similar a las poblaciones de Heredia, Costa Rica (AntWeb 2017). En las obreras de Nariño, la forma de la cápsula cefálica y el largo de los escapos varía, ya que se pueden encontrar cabezas de forma semicuadrada a rectangular y escapos relativamente cortos, por debajo del vértex y también pueden haber poblaciones con cápsulas cefálicas en forma similar a las obreras de Cundinamarca, y escapos largos sobrepasando el vértex; en oposición a las poblaciones de Cundinamarca, las obreras distribuidas en Nariño son de color marrón claro (Figs. 4C-4D), similares en color a las obreras de T. ramulorum saga (AntWeb 2017). Guerrero (en preparación) sugiere que $T$. ramulorum presenta una amplia variación morfológica con relación a su distribución geográfica, por lo cual T. ramulorum puede ser un complejo de especies crípticas (Escárraga y Guerrero 2016).

\section{Agradecimientos}

Muchas gracias a todos los curadores por enviar material y/o permitir visitar las colecciones entomológicas que están a su cargo. Muchas gracias a los revisores anónimos por sus comentarios y sugerencias al contenido del manuscrito. Agradecemos a Mayron E. Escárraga por la generación de las imágenes y mapas presentadas en esta contribución. EIG agradece a la Vicerrectoría de Investigación de la Universidad del Magdalena (UM) por el apoyo a través del programa de Semilleros de Investigadores. RJG agradece a Lina María Ramos por la generación de las planchas que compilan las figuras. Esta es una contribución derivada del proyecto Sistemática y Evolución de las Hormigas Tapinoma Föerster (Formicidae: Dolichoderinae) en Colombia, apoyado financieramente por Colciencias-Universidad del Magdalena a través del acuerdo \# FP44842-008-2015 (código del proyecto 1117-658-42796).

\section{Literatura citada}

ANTWEB. 2017. Disponible en: http://www.AntWeb.org. [Fecha revisión: 1 marzo 2017].
ARMBRECHT, I.; JIMÉNEZ, E.; ALVAREZ, G.; ULLOA-CHACÓN, P.; ARMBRECHT, H. 2001. An ant mosaic in the Colombian rain forest of Chocó (Hymenoptera: Formicidae). Sociobiology 37: 491-509.

BOLTON, B. 1994. Identification guide to the ant genera of the world. Harvard University Press, Cambridge, Massachusetts. $222 \mathrm{p}$.

BOLTON, B. 2017. An online catalog of the ants of the world. Disponible en: http://www.antcat.org/catalog/. [Fecha revisión: 23 enero 2017].

CHACÓN DE ULLOA, P.; JARAMILLO, G. I.; LOZANO, M. M. 2006. Hormigas urbanas en el departamento del Valle del Cauca, Colombia. Revista de la Academia Colombiana de Ciencias Exactas, Físicas y Naturales 30 (116): 435-441.

CUEZZO, F. 2003. Subfamilia Dolichoderinae. pp. 291-297. En: Fernández F. (Ed.). 2003. Introducción a las hormigas de la región Neotropical. Instituto de Investigación de Recursos Biológicos Alexander von Humboldt, Bogotá, Colombia. XXVI + $398 \mathrm{p}$.

DICK, C. W.; BERMINGHAM, E.; LEMES, M. R.; GRIBEL, R. 2007. Extreme long-distance dispersal of the lowland tropical rainforest tree Ceiba pentandra L. (Malvaceae) in Africa and the Neotropics. Molecular Ecology 16: 3039-3049.

DLUSSKY, G. M.; PERKOVSKY, E. E. 2002. Ants (Hymenoptera, Formicidae) from the Rovno Amber. Vestnik Zoologii 36 (5): 3-20.

EMERY, C. 1896. Studi sulle formiche della fauna neotropica XVIIXXV. Bullettino della Società Entomologica Italiana 28: 33-107.

ESCÁRRAGA, M.; GUERRERO, R. 2016. Molecular taxonomy of Tapinoma ramulorum ants group (Formicidae: Dolichoderinae). Boletín del Museo de Entomología de la Universidad del Valle $16(2): 45$.

FABRICIUS, J. C. 1793. Entomologia systematica emendata et aucta. Secundum classes, ordines, genera, species, adjectis synonimis, locis observationibus, descriptionibus. Tome 2. Copenhague. Impensis Christ.Gottl. Proft. 519 p.

FALLING RAIN SOFTWARE, Ltd. 2017. Directory of cities, towns, and regions in Colombia. Global Gazetteer Version 2.3. Disponible en: http://www.fallingrain.com/world/CO/. [Fecha revisión: mayo 2017).

FERNÁNDEZ, F.; SENDOYA, S. 2004. Lista de las hormigas Neotropicales (Hymenoptera: Formicidae). Biota Colombiana 5 (1): 3-9.

FISHER, B. L.; BOLTON, B. 2007. The ant genus Pseudaphomomyrmex Wheeler, 1920 a junior synonym of Tapinoma Föerster, 1850. Zootaxa 1427: 65-68.

FÖERSTER, A. 1850. Hymenopterologische Studien. 1. Formicariae. Aachen: Ernst Ter Meer, 74 p.

GUERRERO, R. J. 2018. Taxonomic identity of the ghost ant, Tapinoma melanocephalum (Fabricius, 1793) (Formicidae: Dolichoderinae). Zootaxa 4410: 497-510.

HARRIS, R. A. 1979. A glossary of surface sculpturing. California Department of Food and Agriculture, Bureau of Entomology 28: $1-31$.

NICKERSON, J. C.; BLOOMCAMP, C. L. 1988. Tapinoma melanocephalum (Fabricius) (Hymenoptera: Formicidae). Entomol Cir. No. 307. Florida: Department of Agriculture and Consumer Service, Division of Plant Industry.

OLAYA-MASMELA, L. D.; ULLOA-CHACÓN, P.; PAYÁN A. 2005. Hormigas (Hymenoptera: Formicidae) en centros hospitalarios del Valle del Cauca como vectores de patógenos nosocomiales. Revista Colombiana de Entomología 31 (2): 183-187.

SHATTUCK, S. O. 1995. Generic-level relationships within the ant subfamily Dolichoderinae (Hymenoptera: Formicidae). Systematic Entomology 20: 217-228.

SMITH, M. R. 1965. House-infesting ants of the eastern United States. Their recognition, biology, and economic importance. United States Department Agriculture Technology Bulletin 1326: 1-105. 
VERGARA-NAVARRO, E. V.; ECHAVARRÍA, H.; SERNA, F. 2007. Hormigas (Hymenoptera: Formicidae) asociadas al arboretum de la Universidad Nacional de Colombia, sede Medellín. Boletín Sociedad Entomológica Aragonesa 40: 497-505.

WARD P. S.; BRADY, S. G.; FISHER, B. L.; SCHULTZ, T. R. 2010. Phylogeny and biogeography of Dolichoderinae ants: effects of data partitioning and relict taxa on historical inference. Systematic Biology 59: 1-21.

WETTERER, J. K. 2009. Worldwide spread of the ghost ant, Tapinoma melanocephalum (Hymenoptera: Formicidae). Myrmecological News 12: 23-33.

WETTERER, J. K.; GUERRERO, R. 2017. Geographic distribution of Tapinoma litorale (Hymenoptera: Formicidae). Florida Entomologist 100 (1): 1-4.
Recibido: 30-nov-2017 • Aceptado: 23-ago-2018

Citación sugerida:

GARCÍA-AVENDAÑO, E. I; GUERRERO, R. J. 2018. Taxonomía y distribución de las hormigas del género Tapinoma (Formicidae: Dolichoderinae) en Colombia. Revista Colombiana de Entomología 44 (2): 223-237 Julio - Diciembre 2018. 